\title{
Vaccine Injury Compensation Programs: Rationale and an overview of the Québec program
}

\author{
Eve Dubé ${ }^{1,2 \star}$, Dominique Gagnon ${ }^{1}$, Noni E MacDonald ${ }^{3}$, Shawn Harmon ${ }^{3}$, \\ Sandani Hapuhennedige ${ }^{4}$
}

\begin{abstract}
Vaccines are among the safest therapeutic agents, and serious adverse events rarely occur. When they do occur, an individual may have to bear some or all of the costs associated with their injuries, seek compensation through litigation or, if available, seek compensation from a publicly-supported Vaccine Injury Compensation Program (VIC Programs). The VIC Programs are "no-fault" compensation schemes in which governments compensate individuals who are harmed by properly manufactured vaccines. There are ethical, legal and practical rationales to support these programs. Worldwide there are 19 countries that have implemented VIC Programs; in the majority of these countries, vaccines are not mandatory. They all have similar processes with respect to process, standard of proof and elements of compensation. In Canada, only the province of Québec has a VIC Program, which has been running successfully since 1985. Concerns with VIC Programs include cost, difficulties assessing causality and concern that such programs may undermine public trust in vaccines; but these concerns can be addressed, especially in high-income countries that can bear the costs and have the capacity to manage the program.
\end{abstract}

This work is licensed under a Creative Commons Attribution 4.0 International License.

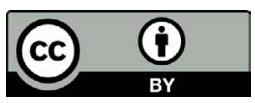

\begin{abstract}
Affiliations
1 Institut national de santé publique du Québec, QC

${ }^{2}$ Centre de recherche du $\mathrm{CHU}$ de Québec - Université Laval, QC

${ }^{3}$ Dalhousie University, Halifax, NS

${ }^{4}$ University of Toronto, Toronto, ON
\end{abstract}

\section{*Correspondence:}

eve.dube@inspq.qc.ca

Suggested citation: Dubé E, Gagnon D, MacDonald NE, Harmon SHE, Hapuhennedige S. Vaccine Injury

Compensation Programs: Rationale and an overview of the Québec program. Can Commun Dis Rep

2020;46(9):305-8. https://doi.org/10.14745/ccdr.v46i09a09

Keywords: vaccine injury, compensation, no-fault insurance, ethical considerations

\section{Introduction}

Vaccines are amongst the safest and most effective tools. Yet, vaccines-like any medical intervention-are not without a possibility of harm, albeit small. Most adverse events following immunization (AEFls) are mild and resolve quickly and completely (e.g. fever, swelling at the injection site, rashes, etc.). In rare instances, however, serious adverse events can occur regardless of proper vaccine design, manufacture and delivery (1). A serious $A E F I$ is defined as one that is life-threatening, requires in-patient hospitalization or prolongation of existing hospitalization, results in persistent or significant disability/incapacity or results in a congenital anomaly/birth defect (2). The absolute risk of serious AEFls is extremely low (e.g. fewer than one per 10 million doses for tetanus toxoid vaccines; 1-2 per one million doses for the inactivated influenza vaccine) (3). At a population level, these rare serious risks are far outweighed by the benefits of high uptake of vaccination. However, this implies that, in rare instances, an individual will suffer from significant consequences for the benefit of others, and that such an event can be anticipated (expected, even), though not necessarily predicted at the individual level (1).
The above state of affairs begs the question: What are the roles and responsibilities of jurisdictions for those who experience a "vaccine injury" (i.e. a serious $A E F I$ ) when given a vaccine recommended by public health? Halabi and Omer (3) identified three types of approaches toward AEFls. While the acute costs of a serious $\mathrm{AEFI}$ are covered through the public healthcare system, for any additional costs, individuals may 1) bear the costs associated with their injuries by themselves, 2) seek compensation through litigation against private-sector actors (i.e. the vaccine manufacturers) or 3) seek compensation from publicly supported systems, or Vaccine Injury Compensation Programs (VIC Programs) (3).

The objective of this article is to provide a rationale and global overview of VIC Programs and to describe the situation in Canada and, specifically, in Québec. This is the seventh in a series of articles produced by the Canadian Vaccination Evidence Resource and Exchange Centre (CANVax). This Centre includes a group of multidisciplinary professionals that identify and create useful resources to foster vaccine uptake. 


\section{Rationale for Vaccine Injury Compensation Programs}

There are a number of reasons why jurisdictions have implemented VIC Programs. As noted by Looker and Kelly, these programs often arise from political and economic pressures, litigation threats and the imperative to ensure an ongoing vaccine supply $(4,5)$. Generally, there are biological, ethical, legal and practical arguments supporting the implementation of VIC Programs (6).

- Biological: Vaccinations are extremely safe, but the possibility of harm in rare instances exists and has been recognized (e.g. anaphylaxis, intussusception from a rotavirus vaccine no longer used)

- Ethical: Vaccination benefits not only the vaccinated individual, but the whole community through herd immunity. Ethical principles of solidarity, reciprocity, fairness and justice all support the implementation of measures to compensate the few individuals who will be harmed by vaccines. These arguments are stronger in jurisdictions where governments use mandatory policies to ensure widespread vaccination

- Legal: We have developed a rights-based society where everyone's physical integrity is, in some measure, guaranteed, and where incursions against this integrity give rise to justifiable claims for redress

- Practical: Tort litigation relating to AEFIs is costly and uncertain, and exposure to this uncertainty and potential liability can discourage manufacturers from producing vaccines. The VIC Programs remove the uncertainty of litigation for manufacturers and ensure the security of vaccine supply. They also help to forge an environment in which vaccine innovation can occur

\section{Global overview}

A recent review has shown that compensation programs have been implemented in 19 jurisdictions worldwide. Interestingly, twelve of the jurisdictions with such programs have no vaccine mandates (Table 1) (4).

The VIC Programs are "no-fault" compensation schemes in which federal or provincial governments compensate individuals who are harmed by properly manufactured vaccines (3).

There is considerable variability in how these programs are administered, who is eligible and which vaccines are covered, the decision-making process for administration and how funds are sourced and allocated (5). Looker and Kelly (1) have conducted an extensive review of common program elements (Table 2).

\section{The Canadian situation}

In Canada, with the exception of Québec, any major health care costs from vaccine injury are covered through the public healthcare system. If a disability occurs, support would likely
Table 1: Jurisdictions with Vaccine Injury Compensation Programs (including the year of introduction)

Vaccination is not mandatory Vaccination is mandatory

Austria (1973)

Denmark (1972)

France (1963)

Finland (1984)

Germany (1961)

Hungary (2005)

Italy (1992)

Iceland (2001)

Republic of Korea (1994)

Japan (1970)

New Zealand (1974)

Slovenia (2004)

Taiwan (1988)

United States (1988)

Norway (1995)

Québec (1985)

Sweden (1978)

Switzerland (1970)

United Kingdom (1979)

Sources: Looker and Kelly, 2011 (1); Attwell et al., 2019 (4)

Table 2: Common elements in Vaccine Injury Compensation Programs

\begin{tabular}{|c|c|}
\hline Element & Comment \\
\hline Administration & $\begin{array}{l}\text { Most compensation programs are enacted } \\
\text { and run by the government at the national or } \\
\text { sub-national levels }\end{array}$ \\
\hline Funding & $\begin{array}{l}\text { National, state or municipal treasuries } \\
\text { Manufacturers' levy } \\
\text { Vaccine tax }\end{array}$ \\
\hline Eligibility & $\begin{array}{l}\text { Only mandatory vaccines } \\
\text { Only vaccines recommended by public health } \\
\text { All licensed vaccines } \\
\text { Only vaccines believed to have an associated } \\
\text { risk (e.g. Vaccine Injury Table) }\end{array}$ \\
\hline Process & $\begin{array}{l}\text { The process is similar in most jurisdictions: } \\
\text { - Threshold injury or disability criteria to be } \\
\text { met before making a claim } \\
\text { - Initial revision by an administrative body } \\
\text { for initial eligibility and compensation } \\
\text { decisions } \\
\text { - Revision by external review committee if a } \\
\text { claim is deemed complex or contentious } \\
\text { - A formalized appeal process for claimants } \\
\text { - Prioritization of timely resolution of claims }\end{array}$ \\
\hline Standard of proof & $\begin{array}{l}\text { "Balance of probabilities" (i.e. more evidence } \\
\text { than not that a vaccine caused the injury) } \\
\text { Probable cause } \\
\text { "Preponderant probability" }\end{array}$ \\
\hline $\begin{array}{l}\text { Elements of } \\
\text { compensation }\end{array}$ & $\begin{array}{l}\text { Lump sum or reimbursement proportional to } \\
\text { the severity of vaccine injury, including: } \\
\text { - Unreimbursed medical costs } \\
\text { - Disability pension } \\
\text { - Non-economic loss, including pain and } \\
\text { suffering } \\
\text { - Death benefits } \\
\text { - Compensation to family } \\
\text { - Reasonable legal costs (in the United } \\
\text { Kingdom, for both successful and } \\
\text { unsuccessful claimants) }\end{array}$ \\
\hline
\end{tabular}


Table 2: Common elements in Vaccine Injury Compensation Programs (continued)

Element

Litigation right
Comment

In most countries, claimants can seek either damage through the courts or compensation through the program, but not both

Other countries adjust compensation payments if damage has been received through the courts

Source: Looker and Kelly, 2011 (1)

come from disability incomes for those who are covered. The only means for compensation beyond this is through litigation.

There is a limited understanding of the number and scope of vaccine-injury related lawsuits in Canada (5). We do know that very few cases reach the courts, and these are often in relation to procedural matters, not the merits of the cases (i.e. requests for certification as class actions, requests to have claims struck, etc.) (7). One exception is Morgan vs. City of Toronto (8), wherein the plaintiff sued the City of Toronto for damages stemming from chronic fatigue syndrome, which she alleged resulted from the city's negligent administration of hepatitis B vaccine in 1994 In dismissing the claim, the Court held that, while the standard for disclosure of risks is very high, not every suspicion of risk constitutes a "known" or "material" risk, and that the city did not breach the standard in failing to warn the plaintiff about possible effects that were not, at the time of the inoculation, considered material. Note that many more cases are adjudicated through bodies such as Workers' Compensation Tribunals and Workplace Safety and Insurance Appeals Tribunals, but no comprehensive survey of the outcomes of these cases have been conducted.

\section{Québec's Vaccine Injury Compensation Program}

The following description comes from the Québec Ministry of Health website (https://www.msss.gouv.qc.ca/en/). In 1979, a five-year-old girl, Nathalie Lapierre, developed viral encephalitis shortly after being vaccinated for measles, and was left severely disabled. Her parents brought an action against the Government of Québec for damages, including those relating to tutoring. In Québec (Attorney-General) vs. Lapierre (9), the Québec Court of Appeal held that, while there was a causal link between the vaccination and the injury, there was no fault on the part of the Province (or the administering nurse), and there was no obligation under Québec law to compensate in the absence of fault. In dismissing Lapierre's appeal, both the Court of Appeal and the Supreme Court of Canada observed that "an obligation independent of any fault in circumstances such as those of the case at bar would be an excellent thing, but it does not exist in our law at present". In the result, perhaps for political reasons, or in recognition of the demands of social justice, the Government of Québec provided some support to the family in this case. Subsequently, in 1985, it introduced its
VIC Program, which was statutorily grounded in a new division of the Public Health Protection Act. A regulation specific to this program was adopted in November 1987, and the first claims for compensation were filed the following year.

The principle of the VIC Program is that the Québec's Minister of Health and Social Services must compensate anyone injured as a result of a voluntary vaccination with a vaccine or immunoglobulins against a disease or infection identified in the regulation, or any compulsory or imposed vaccination. The vaccination must have taken place in Québec, and the claim form must be filed within three years of the injury. The claim is reviewed by an external committee of experts in vaccinology who 1) makes recommendations to the Minister on the existence or lack thereof of a causal link between the injury sustained and the vaccination and 2 ) assesses, if required, the percentage of permanent impairment to the victim's physical or mental integrity, and other elements required regarding compensation.

The Minister then renders a decision. If the claim is rejected, the claimant is informed and has 60 days to file an appeal. If the claim is accepted, the amount of compensation is determined using earnings and medical costs. The Minister has entered into an agreement with the Société de l'assurance automobile du Québec whereby the Société calculates and pays the compensation in cases with a favourable decision. Amounts are calculated pursuant to the rules and regulations prescribed in the Automobile Insurance Act and are identical to those awarded in case of an automobile accident.

As of April 1, 2018, 228 completed claims have been submitted and 187 met the admissibility criteria and were evaluated. Of these 187 cases, 43 claims were accepted, which resulted in $\$ 5.49$ million of compensation paid. There is usually between three and five claims per year, but 11,16 , nine and 28 claims were submitted between 2009 and 2012, respectively. In 2009-2010, 5.7 million Quebecers received the influenza $A(H 1 N 1)$ vaccine, and this increased vaccination rate could explain the increase in claims observed in the three years following the mass vaccination campaigns (10).

\section{Concerns with Vaccine Injury Compensation Programs}

Arguments against VIC Programs are often grounded on the costs of these programs, the difficulties with causality assessment (i.e. determining whether there is a causal relationship between a vaccine and a specific injury) and the concern that these programs can decrease public trust in vaccines and fuel anti-vaccination movements (4).

Some of these concerns regarding VIC Programs have been addressed. The experience in the 19 jurisdictions where such programs have been implemented indicates that costs are both manageable and predictable (7). One caveat, however, is that 17 
of these 19 countries are high-income countries, which means that, on the whole, they can bear the costs and have the capacity to manage the program.

Similarly, the difficulties with causality assessment appear to be resource dependent, as the countries who have adopted VIC Programs have had the expertise to assess vaccine quality and causality of injuries. Finally, to date, there is insufficient evidence to assess the concern regarding the potential to decrease public trust in vaccines. The absence of a VIC Program has not been identified as a major concern amongst those who are hesitant. There is no evidence to show that having VIC Programs support vaccine acceptance; however, when a VIC Program is adopted there could be a communication strategy that reassures the public that, much like accident insurance, if it does occur, they will be covered.

\section{Conclusion}

Many affluent countries have VIC Programs; Canada and the United States are the only G7 countries that do not. There is a strong public health justification for the implementation of VIC Programs. Although there is no direct proof that these programs improve vaccine acceptance, they do help to maintain vaccine supply. If and when other provinces and territories in Canada consider such programs, the ethical, legal, and practical considerations as well as the successful 35-year track record in Québec may help to inform this policy decision.

\section{Authors' statement}

ED - Writing original draft, review and editing

DG - Writing, review and editing

NEM - Writing, review and editing

SHEH - Writing, review and editing

$\mathrm{SH}-$ Writing, review and editing

\section{Competing interests}

E Dubé received grants from the Public Health Agency of Canada, the Québec Ministry of Health and Social Services, les Fonds de recherche du Québec-Santé, the Canadian Institutes of Health Research, the Canadian Immunization Research Network and the Social Sciences and Humanities Research Council of Canada. She is a member of the Canadian Vaccination Evidence Resource and Exchange Centre (CANVax) Team.

NE MacDonald received grants from the Public Health Agency of Canada, the World Health Organization, the Nova Scotia Health Research Foundation, the Canadian Institutes of Health Research, the Canadian Immunization Research Network and the Social Sciences and Humanities Research Council of Canada. She is a member of the CANVax Team.

\section{Acknowledgements}

Production of the Canadian Vaccination Evidence Resource and Exchange Centre (CANVax) briefs has been made possible through funding from the Public Health Agency of Canada. Thank you to the many authors, immunization partners, and reviewers who contribute to CANVax.

\section{Funding}

The development of the Canadian Vaccination Evidence Resource and Exchange Centre Briefs is supported by the Immunization Partnership Funds of the Public Health Agency of Canada.

\section{References}

1. Looker C, Kelly H. No-fault compensation following adverse events attributed to vaccination: a review of international programmes. Bull World Health Organ 2011;89(5):371-8. DOl PubMed

2. World Health Organization. Global Manual on Surveillance of Adverse Events Following Immunization. Geneva (CH): WHO; 2014 (revised 2016; accessed 2019-05-15). https:// www.who.int/vaccine_safety/publications/Global_Manual_ revised_12102015.pdf?ua=1

3. Halabi SF, Omer SB. A Global Vaccine Injury Compensation System. JAMA 2017;317(5):471-2. DOI PubMed

4. Attwell K, Drislane S, Leask J. Mandatory vaccination and no fault vaccine injury compensation schemes: an identification of country-level policies. Vaccine 2019;37(21):2843-8. DOI PubMed

5. Hapuhennedige $S$, Nisbet $C$. A scoping review on vaccine injury compensation. Understanding Canadian Immunization Policy. Background Paper. Simcoe Muskoka District Health Unit. 2017. p. 40.

6. Wilson K, Keelan J. The case for a vaccine injury compensation program for Canada. Can J Public Health 2012 Mar-Apr;103(2):122-4. DOI PubMed

7. Adam, Abudu v. Ledesma-Cadhit et al., 2014 ONSC 5726; Batten v. Boehringer Ingelheim (Canada) Ltd., 2017 ONSC 53; Re Tluchak Estate, 2018 SKQB 311.

8. 2006 CanLII 41574 (ON SC).

9. (1983) 7 DLR (4th) 37 (QC CA), affirmed in Lapierre v. A.G. (Québec), [1985] 1 SCR 241.

10. Government of Québec. Vaccine Injury Compensation Program. Government of Québec (updated 2019; accessed 2019-05-15). https://www.quebec.ca/en/health/advice-andprevention/vaccination/vaccine-injury-compensation-progra $\mathrm{m} / \# \mathrm{c} 3896$ 